osmoprotective molecules in brain cells, and altered membrane ion transport, possibly as a result of hypoxia, is probably responsible for the development of cerebral oedema in diabetic ketoacidosis.

Though the aetiology of the condition is still unclear, management must aim to minimise the risk. Cerebral oedema usually presents 2-24 hours after treatment has started, with abrupt neurological deterioration and coma followed by respiratory arrest. In retrospect warning signs, such as headache, incontinence, and behavioural changes are often present a few hours earlier. The only conventional treatment that may help is mannitol. This is most effective when given soon after the onset of oedema, with over half the reported patients left with mild or no disability. ${ }^{19}$ The only danger is of plasma hyperosmolality after repeated doses. Dexamethasone does not seem to help and hyperventilation may be harmful since the fall in arterial carbon dioxide concentration will reduce cerebral perfusion pressure, predisposing to ischaemic damage.

Finally, in view of the probable role of changes in plasma osmolality, abrupt changes in glucose and electrolyte concentrations should be avoided. Colloid and crystalloid replacement could be alternated during initial rehydration to maintain plasma osmolality while the fluid and electrolyte abnormalities are corrected. When possible, plasma osmo- lality and concentrations of blood glucose and plasma sodium should be monitored and the rates of insulin and saline infusion adjusted to avoid rapid reduction; a fall in osmolality of less than $5 \mathrm{mmol} / \mathrm{h}$ is optimal. By such intensive monitoring it may be possible to reduce the incidence of this devastating complication.

PETER HAMMOND MRC Training Fellow

SIMON WALLIS W Senior Lecturer

Division of Endocrinology and Metabolism, Royal Postgraduate Medical School, London W12 0NN

1 Rosenbloom AL. Intracerebral crises during treatment of diabetic ketoacidosis. Diabetes Care 1990;13:1-32.

2 Krane EJ, Rockoff MA, Wallman JK, Wolfsdorf JI. Subclinical brain swelling in children during treatment of diabetic ketoacidosis. $N$ Engl f Med 1985;312;1147-51.

3 Dillon ES, Riggs HE, Dyer WW. Cerebral lesions in uncomplicated fatal diabetic acidosis. Am ₹ Med Sci 1936;192:360-5.

4 Duck SC, Wyatt DT. Factors associated with brain herniation in the treatment of diabetic ketoacidosis. $\mathcal{F}$ Pediatr 1988;113:10-4.

5 Clements RS, Prockop LD, Winegrad AI. Acute cerebral oedema during the treatment of hyperglycaemia: an experimental model. Lancet 1968;ii:384-6.

6 Arieff AI, Kleeman CR. Effects of hyperglycaemia and rapid lowering of plasma glucose in normal rabbits. F Clin Invest 1973;52:571-83.

Young E, Bradley RF. Cerebral oedema with irreversible coma in severe diabetic ketoacidosis. $N$ Engl f Med 1967;276:665-9.

8 Collins RC, Dobkin BH, Choi DW. Selective vulnerability of the brain: new insights into the pathophysiology of stroke. Ann Intern Med 1989;110:992-1000.

9 Bello FA, Sotos JF. Cerebral oedema in diabetic ketoacidosis in children. Lancet 1990;336:64.

\title{
Assisted conception on the NHS?
}

\section{Many infertile couples could be helped}

Assisted conception, which includes the use of in vitro fertilisation, gamete intrafallopian transfer, and intrauterine insemination, is unusual in many respects. Very few techniques have been introduced into medical practice and developed under the same degree of public and professional scrutiny. Test tube babies raised political, ethical, and social questions such that it is the only branch of British medicine whose practice is highly regulated by statute law. ${ }^{1}$ With few exceptions health authorities have refused to fund assisted conception within the NHS so that its development and delivery have been almost entirely in the private sector. The dearth of well conducted trials of clinical efficacy is therefore unsurprising, although the registration of results through the Voluntary Licensing Authority, Interim Licensing Authority, and now the Human Fertilisation and Embryology Authority has provided a national audit of activity and results. $^{2}$

Steptoe and Edwards tried varying techniques for more than 10 years before the birth of the first baby after in vitro fertilisation in $1978 .{ }^{3}$ Initially the success rates were very low, but they have improved since then owing to several factors. It was soon realised that the pregnancy rate per cycle increased in proportion to the number of embryos transferred, although with it the risk of multiple pregnancy increased. ${ }^{4}$ Current regimens of ovarian stimulation with gonadotrophins after down regulation with agonists of gonadotrophin releasing hormone have resulted in fewer cancelled cycles due to premature discharge of luteinising hormone. ${ }^{5}$ Moreover, it has allowed the recovery of the eggs at times suitable to both woman and doctor. Refinements of the conditions of embryo culture, better instrumentation, and probably a less stressful environment have also contributed to improved results such that many centres are now restricting to two the number of embryos replaced in favourable couples. ${ }^{6}$ The remaining $\stackrel{\circ}{\circ}$ unused embryos may be frozen and used in subsequent $\cong$ cycles.

Little doubt therefore exists that in vitro fertilisation and other forms of assisted conception offer a chance of treatment to some infertile couples who otherwise would remain childless. Two recently published studies suggest that in selected patients cumulative pregnancy rates are similar to those in normal fertile couples. Hull et al found that this was 3 true for couples where the woman was under 40 and the man had normal sperm. ${ }^{8}$ Reviewing the results of in vitro fertilisation for all causes of infertility, Tan et al found that womeno under 34 had comparable pregnancy rates to the normal population. After 35, pregnancy and birth rates fell rapidly. ${ }^{\circ} \rightarrow$ The success rate falls in older women because of difficulty in stimulating multiple follicular development, a reduced implantation rate per embryo, and a higher proportion of N spontaneous miscarriages. All these factors point to fewer $\sigma$ normal oocytes and more embryos with less developmental

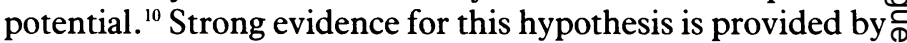
the fact that when donor oocytes are used the pregnancy and? live birth rate for recipient older women is very high."

Why do governments and the World Health Organisation ${ }^{12} \frac{\mathrm{O}}{8}$ have such reservations about a successful treatment for women who would otherwise remain infertile? Some hold the view that such expensive treatment should be accorded a low priority when compared with life saving procedures such aso renal transplantation. WHO points out the risks of the hyperstimulation syndrome and the increased incidence of $\frac{\bar{\sigma}}{\partial}$ abortion and preterm labour associated with multiple preg-nancies, which further drain the limited funds available for health. Analysis of more than 1000 babies born after in vitro fertilisation, however, shows an increase in preterm deliv- 
eries, mostly associated with multiple pregnancies, but no overall increase in congenital abnormalities. ${ }^{13}$

Couples worldwide are prepared to make enormous personal sacrifices to have the chance of having a child. In many European countries the governments directly or, through health insurance, indirectly, provide some assisted conception. While the glamour of test tube babies should not detract from the need to provide a fully comprehensive infertility service, surely it is time that there was better provision of assisted conception in Britain, where Edwards and Steptoe pioneered in vitro fertilisation.

DAVID T BAIRD

Department of Obstetrics and Gynaecology,

Edinburgh University Centre for Reproductive Biology,

Edinburgh EH3 9EW

1 McLaren A. Research on the human conceptus and its regulation in Britain today. $\mathcal{F} R$ Soc Med 1990;83:209-13.
2 Interim Licensing Authority for Human In Vitro Fertilisation and Embryology. Fifth report of the Interim Licensing Authority for Human In Vitro Fertilisation and Embryology. London: ILA, 1990. Steptoe PC, Edwards RG. Birth after the reimplantation of a human embryo. Lancet 1978;i:683. 4 Fishel SB, Edwards RG, Purdy JM, Steptoe PC, Webster J, Walters E, et al. Implantation, abortion and birth after in vitro fertilization using the natural menstrual cycle in follicular stimulation with clomiphene citrate and human menopausal gonadotrophin. foumal of In Vitro Fertilisation and Embryo Transfer 1985;2:123-31.

5 Antoine JM, Salat-Baroux J, Alvarez S, Cornet D, Tiri C, Mandlebaum J, et al. Ovarian Anime JM, Salint Baroux J, stimulation using human monologues in a long 1990;5:565-9.

6 Dawson KJ, Rutherford AJ, Margara RA, Winston RML. Reducing triplet pregnancies following in-vitro fertilisation. Lancet 1991;337:1543-4.

Testart J, Lassalle B, Belaisch-Allart J, Haxout A, Forman R, Rainhorn JD, et al. High pregnancy rate after early human embryo freezing. Fertil Steril 1980;46:268-73.

8 Hull MGR, Eddowes HA, Fahy U, Abuzeid MI, Mills MS, Cahill DJ, et al. Expectations of assisted conception for infertility. BMf 1992;304:1465-9.

9 Tan SL, Royston P, Campbell S, Jacobs HS, Betts J, Mason B, et al. Cumulative conception and live birth rates after in-vitro fertilisation. Lancet 1992;339:1390-4.

10 Declining fertility: egg or uterus? [Editorial.] Lancet 1991;338:285-6.

11 Navot D, Bergh PA, Williams MA, Garrisi GJ, Guzman I, Sandler B, et al. Poor oocyte quality rather than implantation failure as a cause of age-related decline in female fertility. Lance 1991;337:1375-7.

12 World Health Organisation. Consultation on the place of in vitro fertilisation in infertility care. Geneva WHO, 1990. (EUR/ICP/MCH 122(S).) (Summary of report: $B M \mathcal{F} 1992 ; 305$ :facing p 250.)

13 MRC Working Party on Children Conceived by In Vitro Fertilisation. Births in Great Britain resulting from assisted conception, 1978-87. BMF 1990;300:1229-33.

\section{Refugee health}

\section{Requires a comprehensive strategy}

The numbers of refugees and asylum seekers have increased dramatically over the past 20 years. The current conflict in Bosnia alone is estimated to have created one and a half million refugees, the most in Europe since the second world war. Even so, the largest refugee populations originate from the countries of Africa and Asia, and only 5\% of them seek asylum in the industrialised world. ${ }^{1}$ But $5 \%$ of the world's 15 million refugees is still a great many.

In 1991 western Europe registered 540000 asylum seekers - nearly twice the figure for 1989 and more than three times that for 1987. Germany has been the main destination: last year it attracted a record 256000 asylum seekers, who included ethnic Germans from eastern Europe and the former Soviet Union. While the United Kingdom scores low on the list of west European destinations for asylum seekers (coming ninth), flows have increased dramatically. Between 1988 and 1991 the number of refugees arriving in the United Kingdom rose by $500 \%$. Last year the Home Office recorded 44000 applications for asylum, including a growing proportion from unaccompanied refugee children; the numbers are still increasing. ${ }^{2}$ With the open borders policy of the single European market coming into effect at the end of this year, illegal economic migration may confuse the picture and swell the numbers seeking entry into the United Kingdom.

London is the main destination for refugees to the United Kingdom with more than $90 \%$ of all asylum seekers settling there. In 1989 the now disbanded London Strategic Policy Unit estimated that there were 127930 refugees in London, but exact numbers are difficult to obtain because no accurate source of statistics exists at local level. A recent study in two north London regions gave an estimate of 116000 refugees living mostly in the inner city districts. ${ }^{3}$ Although such numbers are not overwhelming, refugees present the health and social services with particular challenges out of all proportion to their number. ${ }^{4}$ Not only do many of them suffer from the stress of insecurity and the effects of persecution, both physical and psychological, but they also encounter difficulties of access to services because of language problems and unfamiliarity with British systems. In addition, they face the health consequences of unemployment and poverty.
Dick has provided a useful classification of the health problems of refugees, ${ }^{5}$ which should also help to define the appropriate responses. Where people lived before becoming refugees (whether in the country or towns) is relevant to their nutritional status and their illnesses. Previous lifestyle and culture will shape the refugees' acceptance and expectations of health care in their new environment. The causes of upheaval, whether political conflict or famine, or both, will have implications for health. Children and elderly people are the most vulnerable, but women refugees also carry a disproportionate share of the problems of displacement. ${ }^{6}$ They invariably are responsible for the children; have often been sexually abused in prison, in flight, or as part of torture; and are often faced with greater responsibilities owing to the breakdown in traditional family and community structures.

The effects of displacement on the mental health of refugees may be profound. Many asylum seekers, already traumatised, are subjected to a hostile reception from the authorities or even detention at the port of entry. The problem is often then exacerbated by a long wait for a decision on their application for asylum. The Home Office takes an average of 53 weeks to deal with such applications, but many people have to wait for 18 months and sometimes for longer than two years. ${ }^{7}$

Several factors have been identified as important in the development of mental illness in displaced people. ${ }^{8}$ These include language difficulties, family separation, hostility from the host population, social isolation, and traumatic experience before displacement. A past history of violence may be particularly important in the life histories of refugees with serious somatic and psychological problems, ${ }^{9}$ yet few health professionals in this country are trained to care for such conditions. Failure to recognise and treat such patients early enough can lead to long term psychological problems. ${ }^{10}$

The specific health needs of refugees require a comprehensive strategy for health and social services that assembles accurate statistics on refugees at the local level, ensures that refugees have equality of access to services, and provides training for staff in refugees' health. The participation of 